\title{
Knowledge, attitude and practices associated with COVID-19 among health care workers: A cross- sectional study in India.
}

\section{Shivkumar Gopalakrishnan}

Government Villupuram Medical College \& Hospital https://orcid.org/0000-0002-4933-1076

Sangeetha Kandasamy ( $\sim$ gvmcforms123@gmail.com )

Government Sivagangai Medical College and Hospital https://orcid.org/0000-0001-8458-512X

Omar A. Almohammed

King Saud University

Bobby Abraham

Government Villupuram Medical College

Monika Senthilkumar

Government Villupuram Medical College \& Hospital

\section{Research Article}

Keywords: Knowledge, Attitude, Practice, COVID-19, Health Care Workers, India

Posted Date: October 7th, 2020

DOl: https://doi.org/10.21203/rs.3.rs-87442/v1

License: (c) (1) This work is licensed under a Creative Commons Attribution 4.0 International License. Read Full License 


\section{Abstract}

Background: In India, SARS-CoV-2 pandemic has caused phenomenal loss of lives and overburdened the health system. Low morale, fatigue and inadequate knowledge among health personnel are perceived threats to pandemic control. Knowledge, Attitude and Practice (KAP) studies among HCWs can identify crucial knowledge gaps and gauge psychological impact. We aimed to assess the COVID-19 related current level of knowledge, attitude and practices among our HCWs.

Methods: A cross-sectional, electronically distributed, questionnaire-based study was conducted among HCWs. The questionnaire identified participants' demographics and the current KAP related to COVID-19. Descriptive statistics were used to present the participants' demographics and Chi-square test to assess differences among the participants' demographics based KAP. $a<0.05$ was used for statistical significance. The association between the knowledge, attitude and practices was assessed using Pearson correlation coefficient $(r)$.

Results: Of 1,429 total participants, $71.9 \%$ belonged to age group $21-40$ years. Female workers constituted $61.5 \%$. Only $40.2 \%$ received any infection control training and $62.7 \%$ relied upon single source of information update. However, $82.9 \%$ of participants had adequate knowledge. Being married, urban dwelling and higher qualification were associated with knowledge adequacy $(p<0.001)$. Interestingly, senior HCWs (age 41-50 years) were least likely to have adequate knowledge (74.1\%). 84.2\% had positive attitude towards COVID. Notably, $83.8 \%$ feared providing care to COVID patient. $93 \%$ practised safety precautions correctly most of the times and training had no influence on practise. Positive correlation was recognized between adequate knowledge and positive attitude $(r=0.26)$.

Conclusion: More than $80 \%$ of HCWs in India had adequate knowledge, positive attitude and practiced safely most of the time. However pitfalls like poor training, knowledge uncertainties and fear of disease acquisition among HCWs need to be addressed. Adverse outcomes can be averted by structured training sessions and psychological support programs for HCWs.

\section{Background}

The pandemic caused by SARS-CoV-2 has swept through the world causing unprecedented loss of lives and livelihood. Successful outbreak containment requires sound knowledge of the disease and a positive attitude among affected population. Research efforts in China revealed that an optimistic attitude among general population was conducive to gain victory over COVID-19 pandemic ${ }^{[1]}$.

India is the second most populous country on the globe with a population density of 382 persons/square $\mathrm{km}^{[2]}$. Recent updates reveal a case load of 35,42,733 with 63,498 COVID-19 deaths, the third highest in the world ${ }^{[3]}$. Overcrowding and low literacy levels establishes India as a fertile ground for COVID-19 propagation. The Knowledge, Attitude and Practise (KAP) of key stakeholders influence the dynamics of pandemic behaviour ${ }^{[4]}$. The human community has seen epidemics before which have evoked anxiety 
and fear responses among affected populations ${ }^{[5]}$. Poor knowledge and improper practices of hospital workers propagate rather than contain the infection. Today, the Indian Health Care Worker (HCW) is walking the tight rope balancing an exhaustive work burden and perceived insecurity to life ${ }^{[6]}$. Going to war with a tired and demoralised work force spells catastrophe for the Health System. As our country bravely battles against the pandemic, HCWs' KAP need to be assessed to identify knowledge gaps and gauge the psychological impact on them.

Previous research works have either unveiled the KAP of general public or investigated the mind set of isolated groups (students, doctors, patients, etc.) preferentially ${ }^{[1,7,8]}$. The information available so far is piecemeal which cannot be construed into a meaningful representation of the wholesome health care team. To our knowledge, this is the first effort in our country to assess the COVID related KAP of the entire health care team.

\section{Methods}

\section{Study design and participants}

A cross-sectional questionnaire-based study was conducted to assess the KAP related to COVID-19 among HCWs in India. The questionnaire was constructed and distributed simultaneously to multiple COVID-19 treatment centres across the country between June $1^{\text {st }}$ and July $30^{\text {th }}$ of 2020 . All HCWs in the age group of 21-70 years and working in COVID treatment centres were considered eligible for the study. They were encouraged to answer the questionnaire distributed electronically and those with poor access or ability to use technology were recruited through printed version of the questionnaire. Their responses were recorded strictly on the basis of anonymity to avoid social desirability bias.

\section{Questionnaire}

A questionnaire was specifically designed for the study using fixed response questions, both multiple choice and yes/no types (Additional file 1) with 2 parts. Part 1 probed the demographic particulars of responders and their consent to participate. Only those who gave consent could access the second part of the questionnaire. Part 2 contained questions assessing knowledge ( 9 items), attitude ( 8 items), and practises (7 items) of the HCW. The questionnaire was synthesised, scaled and scrutinized by the study team in cognizance with field experts. The knowledge items covered aspects about the virus, epidemiology, disease pathology, clinical features and management. The attitude items covered personal perceptions and attitude such as fear, insecurity, optimism, confidence and responsibility. The practice items covered appropriate usage of personal protective equipment (PPE) at work and personal/social life.

The questionnaire was piloted among the first 50 participants and further refined based on feedback. Electronic survey tool (Google forms) was used to distribute the online-survey. The link for accessing the questionnaire was disseminated using e-mail, WhatsApp, and text messages to reach to HCWs across the nation. Survey tool mandated the participants to respond to all the questions without which the forms 
could not complete submission process. Furthermore, the questionnaires were designed both in English and the predominant regional language to overcome language barrier.

\section{Scoring system for the questionnaire}

For knowledge, the participant received one point for each correct answer, and zero for incorrect answer (range 0 to 9). A minimum of 7 points (77\%) was considered as knowledge adequacy. For attitude, two points for positive response, one for neutral and zero for negative response (range 0 to 16). At least 9 points were required to qualify for positive attitude. For practise, two points for right response, one for "Not Sure", and zero for wrong/no responses (range 0 to 14). Participants with at least 11 points were considered to have applied safety practices most of the times.

\section{Statistical analysis}

Descriptive statistics were used to present participant demographics and frequencies of personnel with adequate knowledge, positive attitude and applying safety practices most of the time. The distribution of the participants' KAP based on their demographics was compared using Chi-square test. The association between the knowledge, attitude and practices was assessed using Pearson correlation coefficient $(r)$. Assuming at least $50 \%$ of study population would have adequate knowledge, the required the sample size was 385 . The $a$ level $<0.05$ was used for statistical significance. The data from the questionnaire were coded and analysed using the SAS software, version 9.4 (SAS Institute Inc., Cary, NC, USA).

\section{Results}

A total of 1,429 participants completed the questionnaire. Most responders belonged to age group 21-40 years $(71.9 \%)$ and females outnumbered males $(61.5 \%$ vs $38.5 \%)$. About $80.6 \%$ of all participants were Health Care Professionals (HCP) [physicians, nurses, pharmacists, and laboratory experts], the remaining $19.4 \%$ being non-professional HCW [nursing assistants, para-clinical technicians and sanitary workers] representing the supportive staff in the centres. The demographics of participants are presented in Table 1. Notably, only $40.2 \%$ of the participants had received any infection control training and $62.7 \%$ of participants relied solely upon single source of information. The most common source of information was news media channels (22.8\%) [Figure 1.]

\section{Knowledge}

Participants answering right to knowledge questions ranged between $60.0 \%$ and $99.7 \%$ (Table 2). The question with the least correct response was "K6: Multiple proven curative treatment options are available now for COVID-19 all over the world- Yes/No" for which only $60.0 \%$ responded correctly. Interestingly, $30 \%$ of participants still believed that the pandemic would end in summer because of high temperatures and humidity. Overall, adequate knowledge was documented among $82.9 \%$ of participants. However, only $74.1 \%$ of HCW aged 41-50 years had adequate knowledge. Being married, urban dwelling and higher educational qualification were associated with a higher probability of knowledge adequacy. 
Paradoxically, receiving an infection control training had a negative impact on knowledge scores $(77.7 \%$ vs $86.4 \%, p<0.01$ ) (Table 5 ).

Table1. Demographic characteristics of participants. 


\begin{tabular}{|c|c|}
\hline Characteristic & Number (\%) \\
\hline \multicolumn{2}{|l|}{ Age } \\
\hline $21-30$ years & $576(40.3)$ \\
\hline $31-40$ years & $451(31.6)$ \\
\hline $41-50$ years & $270(18.9)$ \\
\hline $51-60$ years & $102(7.1)$ \\
\hline $61-70$ years & $30(2.1)$ \\
\hline \multicolumn{2}{|l|}{ Gender } \\
\hline Male & $550(38.5)$ \\
\hline Female & $879(61.5)$ \\
\hline \multicolumn{2}{|l|}{ Residential settlement area } \\
\hline Urban & $778(54.4)$ \\
\hline Rural & $651(45.6)$ \\
\hline \multicolumn{2}{|l|}{ Marital status } \\
\hline Married & $461(32.3)$ \\
\hline Single & $968(67.7)$ \\
\hline \multicolumn{2}{|l|}{ Highest educational qualification } \\
\hline High school or less & $266(18.6)$ \\
\hline Bachelor or associate degree & $337(23.6)$ \\
\hline Master degree & $372(26.0)$ \\
\hline Professional or doctoral degree & $454(31.8)$ \\
\hline \multicolumn{2}{|l|}{ Health care professional (HCP) } \\
\hline No & $277(19.4)$ \\
\hline Yes & $1152(80.6)$ \\
\hline \multicolumn{2}{|c|}{ Hospital department for health care professionals $(n=1152)$} \\
\hline Medical & $586(50.9)$ \\
\hline Surgical & $148(12.8)$ \\
\hline Nursing & $203(17.6)$ \\
\hline Laboratory services & $138(12.0)$ \\
\hline
\end{tabular}




\section{Attitude and Practices}

Participants with positive responses to the attitude questions ranged between $16.2 \%$ and $96.6 \%$ (Table 3). The item "A3: I think people who got infected with COVID-19, including health care personnel, were infected due to negligence," evoked a strong agreement from $52.6 \%$ of responders. Moreover, $83.8 \%$ of participants feared approaching a COVID-19 patient despite using PPE. In practice questionnaire, participants following safety practices most of the time ranged between $77.5 \%$ and $96.1 \%$ (Table 4). The lowest response rate was for P2 regarding the right sequence of donning PPE as only $77.5 \%$ of participants were doing it correctly (Table 4).

Most participants demonstrated a positive attitude (84.2\%) towards COVID-19, and practiced safety precautions appropriately (93.0\%). Senior HCW aged 51-60 years had more appreciable attitude scores $(p=0.009)$, and young ones (21-30 years) were the least to follow safety practices $(p<0.001)$. Hitherto female sex, higher qualification and affiliation to clinical departments exerted a significant influence towards positive attitude $(p<0.001)$. Married participants were least likely to have positive attitude or follow safety practices adequately $(p<0.001)$. The demographic distribution of KAP among study responders are depicted in Table 5.

Table 2. . Frequency and percentage of participants with correct responses to the knowledge items on the questionnaire. 
K1. COVID-19 is a contagious disease that is caused by?

K2. The most common manifestation for the COVID-19 is?

K3. The disease can easily spread through?

K4. What is the longest incubation period for COVID-19 before experiencing any symptoms?

K5. Severe cases and death are more common among?

K6. Multiple proven curative treatment options are available now for COVID-19 all over the world?

K7. Most COVID-19 cases are mild and can recover with no treatment?

K8. We know that the pandemic will be over by summer, as the causative microbe is sensitive to high temperature and humidity?

K9. Washing hands with soap and water is effective in eliminating the causative microbe. 
A1. In my opinion, all people in the healthcare system and the community are part of this battle against COVID-19, and should be responsible about their role.

A2. I believe that early detection of COVID-19 cases through mass testing will facilitate or accelerate the control of the COVID-19 pandemic.

A3. I think people who got infected with COVID-19, including health care personnel, were infected due to negligence. (reversely scored)

A4. You have a feel of threat or fear when you become close or provide care to a

A5. I think COVID-19 is just a communicable disease which is being given undue importance. (reversely scored)

A6. I think restricting travels, locking cities, and quarantining all suspected cases are an exaggeration for the current situation. (reversely scored)

A7. The country's efforts will succeed in the battle against COVID-19 pandemic.

A8. I think when COVID-19 pandemic is over many benefits and good things will be seen. to the questionnaire items. 
Table 4

Questionnaire items

Number

(\%)

P1. If I or anyone close to me develop any COVID-19 symptoms, I will seek or recommend to others to seek medical attention.

P2. When I am putting on the personal protective equipment (PPE), I follow the following order: Suit - Mask - Goggles - Gloves.

P3. I have been careful not to carry my mobile phone/pen, etc... inside the COVID-19 ward.

P4. I don't go out unless it is necessary.

P5. When I finish my shift, I dispose the PPE and scrub thoroughly before entering home/quarters.

P6. I sanitise my hands with alcohol based solution before attending to each patient.

P7. After using my PPE, I dispose them in the appropriate colour coded bins.

Table 5. Distribution of adequate knowledge, positive attitude, and appropriate practices based on participants' demographics and characteristics. 


\begin{tabular}{|c|c|c|c|c|c|c|c|}
\hline \multirow[t]{2}{*}{ Variable } & \multirow[t]{2}{*}{ Category } & \multicolumn{2}{|c|}{$\begin{array}{l}\text { Adequate } \\
\text { knowledge } \\
\text { (7/9 points) }\end{array}$} & \multicolumn{2}{|c|}{$\begin{array}{l}\text { Positive Attitude } \\
\text { (9/16 points) }\end{array}$} & \multicolumn{2}{|c|}{$\begin{array}{l}\text { Appropriate } \\
\text { practices } \\
\text { (11/14 points) }\end{array}$} \\
\hline & & N (\%) & $P$ & N (\%) & $p$ & $\mathrm{~N}(\%)$ & $P$ \\
\hline Overall & & $\begin{array}{l}1185 \\
(82.9)\end{array}$ & - & 1203(84.2) & & $\begin{array}{l}1329 \\
(93.0)\end{array}$ & \\
\hline \multirow{5}{*}{$\begin{array}{l}\text { Age } \\
\text { (in years) }\end{array}$} & $21-30$ & $\begin{array}{l}491 \\
(85.2)\end{array}$ & \multirow[t]{5}{*}{$<0.001$} & 475 (82.5) & \multirow[t]{5}{*}{0.009} & $\begin{array}{l}509 \\
(88.4)\end{array}$ & \multirow[t]{5}{*}{$<0.001$} \\
\hline & $31-40$ & $\begin{array}{l}386 \\
(85.6)\end{array}$ & & 393 (87.1) & & $\begin{array}{l}428 \\
(94.9)\end{array}$ & \\
\hline & $41-50$ & $\begin{array}{l}200 \\
(74.1)\end{array}$ & & 221 (81.9) & & $\begin{array}{l}262 \\
(97.0)\end{array}$ & \\
\hline & $51-60$ & $\begin{array}{l}83 \\
(81.4)\end{array}$ & & 93 (91.2) & & $\begin{array}{l}102 \\
(100)\end{array}$ & \\
\hline & $61-70$ & $\begin{array}{l}25 \\
(83.3)\end{array}$ & & $21(70.0)$ & & $\begin{array}{l}28 \\
(93.33)\end{array}$ & \\
\hline \multirow[t]{2}{*}{ Gender } & Male & $\begin{array}{l}455 \\
(82.8)\end{array}$ & \multirow[t]{2}{*}{0.875} & 418 (76.0) & \multirow[t]{2}{*}{$<0.001$} & $\begin{array}{l}512 \\
(93.1)\end{array}$ & \multirow[t]{2}{*}{0.917} \\
\hline & Female & $\begin{array}{l}730 \\
(83.1)\end{array}$ & & 785 (89.3) & & $\begin{array}{l}817 \\
(93.0)\end{array}$ & \\
\hline \multirow[t]{2}{*}{ Marital status } & Single & $\begin{array}{l}777 \\
(80.3)\end{array}$ & \multirow[t]{2}{*}{$<0.001$} & 835 (86.3) & \multirow[t]{2}{*}{0.002} & $\begin{array}{l}932 \\
(96.3)\end{array}$ & \multirow[t]{2}{*}{$<0.001$} \\
\hline & Married & $\begin{array}{l}408 \\
(88.5)\end{array}$ & & $368(79.8)$ & & $\begin{array}{l}397 \\
(86.1)\end{array}$ & \\
\hline \multirow[t]{2}{*}{ Residential area } & Urban & $\begin{array}{l}703 \\
(90.4)\end{array}$ & \multirow[t]{2}{*}{$<0.001$} & 665 (85.5) & \multirow[t]{2}{*}{0.143} & $\begin{array}{l}723 \\
(92.9)\end{array}$ & \multirow[t]{2}{*}{0.908} \\
\hline & Rural & $\begin{array}{l}482 \\
(74.0)\end{array}$ & & 538 (82.6) & & $\begin{array}{l}606 \\
(93.1)\end{array}$ & \\
\hline \multirow[t]{2}{*}{$\begin{array}{l}\text { Received infection } \\
\text { control training }\end{array}$} & No & $\begin{array}{l}783 \\
(86.4)\end{array}$ & \multirow[t]{2}{*}{$<0.001$} & 712 (83.4) & \multirow[t]{2}{*}{0.305} & $\begin{array}{l}786 \\
(92.0)\end{array}$ & \multirow[t]{2}{*}{0.082} \\
\hline & Yes & $\begin{array}{l}447 \\
(77.7)\end{array}$ & & $491(85.4)$ & & $\begin{array}{l}543 \\
(94.4)\end{array}$ & \\
\hline \multirow[t]{2}{*}{$\begin{array}{l}\text { Health care } \\
\text { professional }\end{array}$} & No & $\begin{array}{l}167 \\
(60.3)\end{array}$ & \multirow[t]{2}{*}{$<0.001$} & 243 (87.7) & \multirow[t]{2}{*}{0.059} & $\begin{array}{l}263 \\
(94.9)\end{array}$ & \multirow[t]{2}{*}{0.158} \\
\hline & Yes & $\begin{array}{l}1018 \\
(88.4)\end{array}$ & & $960(83.3)$ & & $\begin{array}{l}1066 \\
(92.5)\end{array}$ & \\
\hline $\begin{array}{l}\text { Educational } \\
\text { achievement }\end{array}$ & $\begin{array}{l}\leq \text { High } \\
\text { school }\end{array}$ & $\begin{array}{l}152 \\
(57.1)\end{array}$ & $<0.001$ & 228 (85.7) & $<0.001$ & $\begin{array}{l}258 \\
(97.0)\end{array}$ & \\
\hline
\end{tabular}




\begin{tabular}{|c|c|c|c|c|c|c|c|}
\hline & $\begin{array}{l}\text { Bachelor or } \\
\text { associate }\end{array}$ & $\begin{array}{l}265 \\
(78.6)\end{array}$ & & $250(74.2)$ & & $\begin{array}{l}319 \\
(94.7)\end{array}$ & \multirow[t]{3}{*}{$<0.001$} \\
\hline & Master & $\begin{array}{l}338 \\
(90.9)\end{array}$ & & $308(82.8)$ & & $\begin{array}{l}324 \\
(87.1)\end{array}$ & \\
\hline & Doctoral & $\begin{array}{l}430 \\
(94.7)\end{array}$ & & 417 (91.9) & & $\begin{array}{l}428 \\
(94.3)\end{array}$ & \\
\hline \multirow{6}{*}{$\begin{array}{l}\text { Hospital } \\
\text { department for } \\
\text { HCP }(n=1152)\end{array}$} & Medical & $\begin{array}{l}533 \\
(91.0)\end{array}$ & \multirow[t]{6}{*}{$<0.001$} & $500(85.3)$ & $<0.001$ & $\begin{array}{l}531 \\
(90.6)\end{array}$ & \multirow[t]{6}{*}{0.097} \\
\hline & Surgical & $\begin{array}{l}137 \\
(92.6)\end{array}$ & & 132 (89.2) & & $\begin{array}{l}139 \\
(93.9)\end{array}$ & \\
\hline & Nursing & $\begin{array}{l}173 \\
(85.2)\end{array}$ & & $162(79.8)$ & & $\begin{array}{l}195 \\
(96.1)\end{array}$ & \\
\hline & Laboratory & $\begin{array}{l}124 \\
(89.9)\end{array}$ & & 113 (81.9) & & $\begin{array}{l}127 \\
(92.0)\end{array}$ & \\
\hline & $\begin{array}{l}\text { Other para- } \\
\text { clinical }\end{array}$ & $\begin{array}{l}31 \\
(63.3)\end{array}$ & & 31 (63.3) & & $\begin{array}{l}48 \\
(98.0)\end{array}$ & \\
\hline & Pharmacy & $\begin{array}{l}20 \\
(71.4)\end{array}$ & & $22(78.6)$ & & $\begin{array}{l}26 \\
(93.0)\end{array}$ & \\
\hline
\end{tabular}

\section{KAP of Health Care Professionals (HCP) vs Non Professional Health Care Workers.}

Professionals had better level of knowledge $(p<0.001)$ as compared to nonprofessional participants [Table 5]. However they did not differ based on positive attitude and appropriate practices. Interestingly, HCPs in clinical departments had significantly better knowledge and positive attitude than those of paraclinical departments $(p<0.001)$. There was no significant difference however in safety practices of clinical and para-clinical department workers.

\section{Correlation between the KAP}

The findings from the correlation analysis indicated the presence of a positive but weak correlation between adequate knowledge and positive attitude $(r=0.26, p<0.001)$, having adequate knowledge and practicing appropriately most of the time $(r=0.05, p=0.047)$, and having positive attitude and practicing appropriately most of the times $(r=0.09, p<0.001)$ [Table 6].

Table 6. Correlation between adequate knowledge, positive attitude, and appropriate practices. 


\begin{tabular}{|c|c|c|c|c|c|c|c|}
\hline \multirow[t]{2}{*}{ Scales } & & \multicolumn{2}{|c|}{$\begin{array}{l}\text { Having adequate } \\
\text { level of knowledge }\end{array}$} & \multicolumn{2}{|c|}{$\begin{array}{l}\text { Having } \\
\text { positive } \\
\text { attitude }\end{array}$} & \multicolumn{2}{|c|}{$\begin{array}{l}\text { Practicing appropriately } \\
\text { most of the time }\end{array}$} \\
\hline & & Yes & No & Yes & No & Yes & No \\
\hline \multirow[t]{2}{*}{$\begin{array}{l}\text { Having adequate level } \\
\text { of knowledge }\end{array}$} & Yes & & & $\begin{array}{l}1045 \\
(73.1)\end{array}$ & $\begin{array}{l}140 \\
(9.8)\end{array}$ & 1119 (78.3) & $66(4.6)$ \\
\hline & No & & & $\begin{array}{l}158 \\
(11.1)\end{array}$ & $\begin{array}{l}86 \\
(6.0)\end{array}$ & $210(14.7)$ & $34(2.4)$ \\
\hline \multirow[t]{2}{*}{ Having positive attitude } & Yes & $r=0.26$ & & & & 1125 (78.7) & 78 (5.5) \\
\hline & No & $p<0.001$ & & & & $204(14.3)$ & $22(1.5)$ \\
\hline \multirow{2}{*}{$\begin{array}{l}\text { Practicing appropriately } \\
\text { most of the time }\end{array}$} & Yes & $r=0.05$ & & \multicolumn{2}{|c|}{$r=0.09$} & & \\
\hline & No & $p=0.047$ & & \multicolumn{2}{|c|}{$p<0.001$} & & \\
\hline
\end{tabular}

Above the leading diagonal are frequency and \% in the interaction between the scales and below are the correlation coefficients $(r)$ between the scales and the $p$-values for the significance of the correlation.

\section{Discussion}

The invasion of human race by SARS-CoV-2 has claimed 8,38,934 lives till date besides causing economic devastation of developing countries ${ }^{[2]}$. Presently, India is cruising through second stage of pandemic progression (multiple clusters), just short of community transmission ${ }^{[2]}$. Realistic appreciation of the situation warrants critical assessment of the mental preparedness of the frontline HCWs who take the heat of the onslaught. We therefore aimed to assess the KAP of Indian HCWs of COVID-19 treatment centres. We found that $82.9 \%$ of HCWs had adequate knowledge, $84.2 \%$ displayed positive attitude, and $93.0 \%$ adhered to safety practices most of the times.

In this study a cumulative $82.9 \%$ of participants possessed adequate knowledge about COVID-19, and HCWs who were married, professionals, urban dwellers and with higher educational qualification had more probability of adequate knowledge than the rest. Interestingly, it was observed that HCWs of age group 41-50 years were lagging far behind others in knowledge aspect. HCWs of this age are generally senior doctors, nursing superintendents, and senior supervisors of paramedical departments. Probable reason for this deficit could be predominant administrative engagements rather than clinical exposure in this group. Relative knowledge inadequacy among senior HCWs is a cause for concern as they are decision makers in most institutes. A recent survey conducted at Mumbai among HCP also revealed only $71.2 \%$ adequacy of knowledge and akin to our study, administrative and paramedical staff performed poorly in knowledge ${ }^{[10]}$. In Pakistan, Saqlain et al. reported that $93 \%$ of HCWs possessed adequate 
knowledge $\mathrm{e}^{[11]}$. The knowledge figures appeared less in our survey probably because of confounding effect of $19.4 \%$ of non- professional HCWs.

Our survey showed that $62.7 \%$ of HCWs relied only upon single source of information for knowledge update. Disturbingly, the most frequent source was news media channels (22.8\%) (Figure 1). In the era of evidence based medicine, the HCW's reliance on non-scientific sources of information is deemed less beneficial for the patient community. This observation could not be dispensed as a regional phenomenon because Saqlain et al. also endorsed the same finding in his survey ${ }^{[11]}$. Of concern was that only $40.2 \%$ of HCWs ever had any infection control training. A similar report from a multicentre study in India highlighted that only $56.18 \%$ of doctors in India had received training related to COVID-19, and less than $50 \%$ were satisfied with the quality of the training ${ }^{[6]}$. Ironically training had a significant negative impact on knowledge scores in our study population $(p<0.001)$. Resource and time shortage make HCW's training, the Achille's heel of health regulatory bodies, more so during pandemic times. Yet this lacuna cannot be left unaddressed and we recommend decentralisation of training programmes at the institute level with feedback evaluation by the Ministry of Health.

Among the significant knowledge gaps, notable ones were regarding treatment aspects and pandemic myths [K6 \& K8 of Table 2]. 40\% of participants believed that many curative treatment options are available for COVID-19 which reflects poor reliance on authenticated information source. Also, 30.4\% were of the opinion that the pandemic would end in summer due to humid climate. Despite the fact that WHO houses a section on "Myth Busters" in its official website ${ }^{[3]}$ such misbeliefs floating among HCWs is worrisome.

This survey identified positive attitude among $84.2 \%$ of the responders. Among all, $96.6 \%$ confirmed having a sense of responsibility towards their role in the pandemic [Table 3]. It was encouraging to note that $73.3 \%$ recorded an optimistic outlook of COVID-19 outcome in our country. However, it was offset by $84.8 \%$ of participants harbouring deep rooted fear when caring for COVID-19 patients. The medical fraternity often find it difficult to come to terms with looming uncertainties during an outbreak. A recent nationwide survey conducted among doctors identified depression and anxiety among $35 \%$ of the responders $^{[9]}$. The MERS epidemic of 2012 had seen a phenomenal impact on the psychosocial wellbeing of doctors involved patient care activities ${ }^{[12]}$. Disease acquisition fear among HCWs jeopardizes delivery of optimal care to the patient and forecasts adverse outcome ${ }^{[13,14]}$. Singh et al. observed that shortage of resources and endless hours of COVID duties have wreaked havoc on the morale of HCWs in India ${ }^{[6]}$. In our study we were able to identify factors conducive to negative attitude which included age (61-70 years), male sex, being married, lower educational qualification and working in para-clinical departments $(p<0.05)$. Care giver fatigue is an ominous sign and we urge the Ministry of Health to look into this need as a priority. Stress relieving manoeuvres for HCWs like Yoga, peer group activities and adequate off-duty hours could be our insurance in this regard.

The study found that $93 \%$ of the participants reported good adherence to safety practices and the relative lack of training didn't seem to adversely affect the same. However, younger aged (21-30 years) and 
married HCWs were less likely to follow sound safety practice; probably due to inexperience and heightened confidence $(p<0.001)$. The weakest link in the chain was donning procedure which only $77.5 \%$ of HCWs practised properly [Table 4]. A related study among doctors in India revealed that $94 \%$ used face masks appropriately and $95 \%$ regularly resorted to hand hygiene ${ }^{[9]}$. The efforts of the Ministry of Health in promulgating awareness among HCWs about safety practices deserves commendation at this juncture. Interestingly, we observed that good practices were uniformly followed by the entire spectrum of HCW population with insignificant differences between the professional and non-professional groups. This was in contradiction to the results observed in Pakistan where pharmacists adhered to infection control practices more than other $\mathrm{HCWs}^{[11]}$. Interestingly, $\mathrm{HCW}$ s with the lowest qualification were the best safety practitioners $(p<0.001)$ [Table 5]. This paradox is a pseudo phenomenon since most of these staff are of lower cadre [Stretcher bearers, nursing assistants, etc.] who are constantly monitored and perform health care activities under supervision.

We observed that knowledge adequacy correlated with positive attitude albeit weakly $(r=0.26)$.The finding mirrors similar research observations performed in neighbouring countries ${ }^{[1,11]}$. Moreover, results of KAP studies conducted among people who experienced the SARS pandemic in 2003 and MERS in 2012 reiterate similar observations wherein adequate knowledge, positive attitude and widespread adherence to safety practices enabled victory over the disease ${ }^{[1,15,16]}$. The study identified important knowledge gaps, attitudinal differences and practice variations among HCWs in India which leaves a lot of space for improvement. Remedial measures suggested include targeted training and mental health programs for HCWs, capacity building of health facilities and curb on social media disseminating fear.

\section{Limitation}

The majority of the study participants (80.6\%) were HCP and only $19.4 \%$ constituted lower cadre staff (technicians, nursing assistants, sanitary workers, etc.). Hence, caution should be exercised in extrapolating the findings of this study to the entire HCW population. However, the only difference between the two groups was in the knowledge aspect which is something that we would expect. Furthermore, the study recruited participants working in high case load COVID-19 centres spanning the country. Their KAPs are shaped by intense exposure which distinguishes them from workers in non COVID-19 hospitals and primary care setup. The study results largely reflect the KAP of HCWs involved in the care of COVID-19 patients and the recommendations therein are applicable to this subset only. Therefore generalization of these findings to all HCWs would lose validity.

\section{Conclusion}

The study found the vast majority of HCWs had adequate level of knowledge, positive attitude and were practicing safely most of the time. However, there were many uncertainties in the KAP of our target population which need to be resolved. First of all, HCWs' infection control training status was far from satisfactory. Secondly, fear of disease acquisition among HCWs was recognized and may negatively impact patient care. Finally, considerable demographic heterogeneity was revealed in the KAP of HCWs 
which can be targeted by focussed educational and psychological training programs. Summing up, the authors conclude that there is a lot of scope for improvement in this aspect of the country's pandemic control strategy which could pave the way for better outcomes. With SARS-CoV-2 still on the rampage, it is time that the country takes a second look at the weak links disabling COVID-19 warriors.

\section{Declarations}

\section{Ethics approval:}

All the study participants gave written informed consent. The study was approved by the Institutional Ethics Committee of Government Villupuram Medical College and Hospital, Tamil Nadu, India.

Consent for publication: Not applicable.

\section{Availability of data and materials:}

The datasets used and/or analysed during the current study are available from the corresponding author on reasonable request.

Competing interests: The authors declare that they have no competing interests.

\section{Funding:}

This conduct of the research was not funded by funding agencies in the public, commercial, or not-forprofit sectors. However, the publication charges as applicable are likely to be covered by the Research Supporting Project [RSP-2020/77], of King Saud University, Riyadh, Saudi Arabia.

\section{Authors' contributions:}

SG designed the study, worked for data interpretation, and drafted the manuscript. SK conceptualized the study, helped in data acquisition and manuscript revision. OA co-designed the research, was the data analyst and helped in manuscript revision. BA acquired and interpreted the data, helped in manuscript drafting. MS refined study design, contributed to data acquisition, and helped in manuscript drafting. All the authors have approved the submitted version of the manuscript and agreed to be accountable for the contents of the same.

\section{Acknowledgement:}

The authors acknowledge the help and support of all HCWs who participated in this survey for sharing their views on the subject.

\section{Abbreviations}

KAP: Knowledge, Attitude, Practice 
HCW: Health Care Worker

HCP: Health Care Professional

COVID-19: Novel Corona Virus Disease 2019

SARS-CoV-2: Severe Acute Respiratory Syndrome- Corona Virus -2

PPE: Personal Protective Equipment

\section{References}

[1] Zhong B-L, Luo W, Li H-M, Zhang Q-Q, Liu X-G, Li W-T et al. Knowledge, attitudes, and practices towards COVID-19 among Chinese residents during the rapid rise period of the COVID-19 outbreak: a quick online cross-sectional survey. Int J Biol Sci 2020;16: 1745-52. https://doi.org/10.7150/ijbs.45221

[2] National Institution for Transforming India. State statistics: population density.

[https://www.niti.gov.in/niti/content/population-density-sq-km]; 2011 [Accessed August 26, 2020]

[3] World Health Organization. Coronavirus Disease 2019 (COVID-19) situation reports.

[https://www.who.int/emergencies/diseases/novel-coronavirus-2019/situation-reports]; [Accessed August 30, 2020.]

[4] Ajilore K, Atakiti I, Onyenankeya K. College students' knowledge, attitudes and adherence to public service announcements on Ebola in Nigeria: Suggestions for improving future Ebola prevention education programmes. Health Educ J 2017;76: 648-60. https://doi.org/10.1177/0017896917710969

[5] Person B, Sy F, Holton K, Govert B, Liang A. Fear and stigma: the epidemic within the SARS outbreak. Emerg Infect Dis 2004;10: 358-63. https://doi.org/10.3201/eid1002.030750

[6] Singh H, Sharma S. Concerns of Frontline Doctors in India during COVID-19: A Cross-Sectional Survey. Indian J Public Health 2020;64: 237-9. https://doi.org/10.4103/ijph.IJPH_472_20

[7] Tachfouti N, Slama K, Berraho M, Nejjari C. The impact of knowledge and attitudes on adherence to tuberculosis treatment: a case-control study in a Moroccan region. Pan Afr Med J 2012;12: 52.

[8] Olum R, Kajjimu J, Kanyike AM, Chekwech G, Wekha G, Nassozi DR et al. Perspective of Medical Students on the COVID-19 Pandemic: Survey of Nine Medical Schools in Uganda. JMIR Public Health Surveill 2020;6: e19847. https://doi.org/10.2196/19847

[9] Chatterjee S, Bhattacharyya R, Bhattacharyya S, Gupta S, Das S, Banerjee B. Attitude, practice, behavior, and mental health impact of COVID-19 on doctors. Indian J Psychiatry 2020;62: 257-65. https://doi.org/10.4103/psychiatry.IndianJPsychiatry_333_20 
[10] Modi PD, Nair G, Uppe A, Modi J, Tuppekar B, Gharpure AS et al. COVID-19 Awareness Among Healthcare Students and Professionals in Mumbai Metropolitan Region: A Questionnaire-Based Survey. Cureus 2020;12: e7514. https://doi.org/10.7759/cureus.7514

[11] Saqlain M, Munir MM, Rehman SU, Gulzar A, Naz S, Ahmed Z et al. Knowledge, attitude, practice and perceived barriers among healthcare workers regarding COVID-19: a cross-sectional survey from Pakistan. J Hosp Infect 2020;105: 419-23. https://doi.org/10.1016/j.jhin.2020.05.007

[12] Um DH, Kim JS, Lee HW, Lee SH. Psychological Effects on Medical Doctors from the Middle East Respiratory Syndrome (MERS) Outbreak : A Comparison of Whether They Worked at the MERS Occurred Hospital or Not, and Whether They Participated in MERS Diagnosis and Treatment. J Korean Neuropsychiatr Assoc 2017;56: 28-34. https://doi.org/10.4306/jknpa.2017.56.1.28

[13] Lai J, Ma S, Wang Y, Cai Z, Hu J, Wei N et al. Factors Associated With Mental Health Outcomes Among Health Care Workers Exposed to Coronavirus Disease 2019. JAMA Netw Open 2020;3: e203976-e. https://doi.org/10.1001/jamanetworkopen.2020.3976

[14] Tan BYQ, Chew NWS, Lee GKH, Jing M, Goh Y, Yeo LLL et al. Psychological Impact of the COVID-19 Pandemic on Health Care Workers in Singapore. Ann Intern Med 2020;173: 317-20. https://doi.org/10.7326/M20-1083

[15] Jiao J-g, Tang X-I, Li H-w, Chen J, Xiao Y, Li A. Survey of knowledge of villagers in prevention and control of SARS in Hainan Province. China Tropical Medicine 2005;5: 703-5.

[16] Almutairi KM, Al Helih EM, Moussa M, Boshaiqah AE, Saleh Alajilan A, Vinluan JM et al. Awareness, attitudes, and practices related to coronavirus pandemic among public in Saudi Arabia. Fam Community Health 2015;38: 332-40. https://doi.org/10.1097/FCH.0000000000000082

\section{Additional Files}

"Additiional file 2. STROBE checklist for cross sectional studies" was not provided with this version of the manuscript.

\section{Figures}


News media channels

Ministry of health
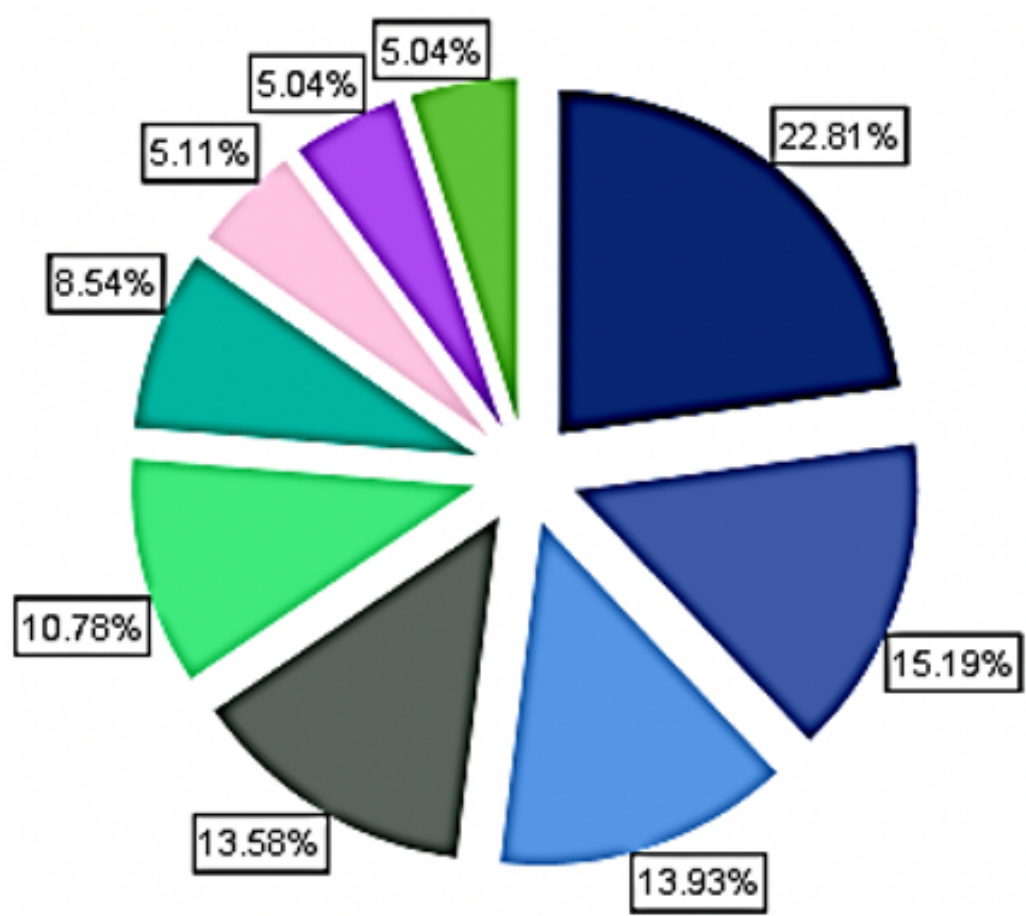

International health organization websites

OOther combination of sources

Social media

Ministry of health and news media channels

All sources of infomation

News media channels and social media

Ministry of health, news media channels, and social media

Figure 1

Main sources of information among Health Care Workers.

\section{Supplementary Files}

This is a list of supplementary files associated with this preprint. Click to download.

- KAPquestionnaireParts12..docx 